\title{
A Rolling Horizon Rescheduling Strategy for Flexible Energy in a Microgrid
}

\author{
Martin P. Marietta $^{\# 1}$, Moisès Graells ${ }^{\# 2}$ Josep M. Guerrero ${ }^{\# 3}$ \\ \# Chemical Engineering Department, Universitat Politècnica de Catalunya \\ EUETIB, C/ Comte d'Urgell 187, 08028-Barcelona, Spain \\ martin.pablo.marietta@estudiant.upc.edu \\ ${ }^{2}$ moises.graells@upc.edu \\ \# Department of Energy Technology, Aalborg University \\ Pontoppidanstrcede 101, 79, 9220, Aalborg, Denmark \\ joz@et.aau.dk
}

\begin{abstract}
In this work an Energy Management System (EMS) prototype for an isolated renewable-based microgrid is presented. The proposed management model not only considers the management of energy sources (generation) but also includes the possibility of flexible timing of energy consumptions (demand management) by modelling controllable and uncontrollable loads. The EMS consists of two stages: first a deterministic management model is formulated and subsequently is integrated into a rolling horizon control strategy, in which the actions on microgrid devices respond to an optimization criterion related to the estimation of the future system behaviour that is continually predicted by updatable forecasts in order to reduce uncertainty in both, production capacity and energy demand. Finally, this contribution presents and discusses a case study where the results of the operation with and without optimal demand management for the same group of loads are evaluated.
\end{abstract}

Keywords: Energy management system, demand management, rolling horizon control strategy.

\section{INTRODUCTION}

The energy worldwide scenario allows foreseeing that future power systems will migrate gradually from large traditional generation systems to more flexible ones. In this new context, large generation plants will coexist with distributed generation technologies, storage devices, and power electronics-based controls.

In-situ and distributed generation, and the connection of Distributed Energy Resources (DERs) to power grids, appears as an efficient alternative and has the advantage of not requiring large transmission lines and distribution. In this way, communities isolated from power supply networks can take advantage of this scheme using renewable energy.

To properly exploit the distributed generation potential, Energy Storage Systems (ESSs) need to be integrated to renewable energy resources to cope with the problem of the variability of supply. The interconnection of DERs and loads constitutes a typical microgrid and its operation needs special protection, control and energy management systems in order to ensure reliable, secure and economical operation.

This work focuses on the Energy Management Systems (EMS) that is conceptually a central controller provided with the relevant information for each DER within the microgrid (e.g., cost functions, technical characteristics, network parameters and mode of operation) as well as information from some forecasting system [1]. The EMS objective is to determine an optimal (or near optimal) operations schedule maximizing the economic performance of the system.

This work addresses such an optimization problem by means of mathematical programming tools.

To perform this task the EMS needs a model of energy management of the microgrid. In this paper the proposed model is integrated into a predictive control strategy where after the optimization, actions on the system are planned for a prevision period but apply in the immediate execution interval, then the system state is sampled and a new optimization is performed. Thus, the prediction horizon is sliding over the time [2].

In the field of microgrids, there are several works relating to EMS working with a rolling horizon control strategy. In [3], Dagdougui et al. present a model representing an integrated hybrid renewable microgrid consisting of a electrolyzer, an hydroelectric plant, some pumping stations, wind turbines, and a fuel cell. The objective is to satisfy the hourly variable electric, hydrogen, and water demands. Sanseverino et al. [4] use a non-dominated sorting genetic algorithm to solve a multi-objective optimization problem. The system proposed is a planning and execution scheduler for the RESs satisfying demands levels given by forecasts. Parisio and Glielmo in [5] present a preliminary study on applying a model predictive control approach to a problem of optimizing microgrid operations while satisfying a time-varying request. PalmaBehnke et al. [6] design an EMS for a renewable based microgrid and a neural network for two-day-ahead electric consumption forecasting. The EMS provides online set points for DERs and signals to consumers for shift loads. The goal is to compare different configurations in a real microgrid composed of PV panels, two wind turbines, a diesel generator and an ESS.

In this work the contributions are: (i) the consideration of the Demand Management (DM) in a rolling horizon control strategy; (ii) $\mathrm{DM}$ is performed from a flexible demand modeling; (iii) the proposed model is formulated using MixedInteger Linear Programming (MILP) which is solved with a commercial solver. 
The rest of the paper is organized as follows: Section II describes the operation of the EMS, proposes the optimization problem and presents the model algebraic representation while Section III shows how the rolling horizon strategy works. A case study where the microgrid operation with DM is evaluated is proposed in Section IV. Section V shows the simulations results and Section $\mathrm{V}$ concludes the paper.

\section{ENERGY MANAGEMENT MODEL}

\section{A. Nomenclature}

The forecast, the parameters and the decision, binary and auxiliary variables used in the model are described in Tables I, II and III and IV respectively.

The used subscripts are:

$\begin{array}{ll}i=i 1 \ldots I & \text { Renewable power sources } \\ u=u 1 \ldots U & \text { Non-renewable power sources } \\ j=j 1 \ldots J & \text { Controllable loads } \\ r=r 1 \ldots R & \text { Repetition of load } \mathrm{j} \\ v=v 1 \ldots V_{u} & \text { Linear segments of the demand curve of a } \\ t=t 1 \ldots t \zeta \ldots T & \text { source } \mathrm{u} \\ & \text { Time intervals }(\zeta \text { is the time interval number) }\end{array}$

\section{B. EMS Operation}

The model contemplates renewable and non-renewable energy from micro-sources, an ESS and a set of energy loads. The EMS manages power generation and loads timing while minimizing operational costs.

EMS block chart is shown in Fig. 1: the EMS provides the set points for the microgrid devices $(P(t, i), P d(u, t), P \operatorname{chg}(t)$ and $P d c g(t))$ and the schedule of controllable loads $(T s(j, r)$, $T f(j, r))$ from the forecast information $(\operatorname{Pmax}(t, i), \operatorname{Dcril}(t))$ and the microgrid state at period t-1 $(C H G(t-1), B g 0(u))$. Other forecast data are, Preal(t-1), actual power generated by REDs; and $U L D(t-1)$, the uncontrollable load demand.

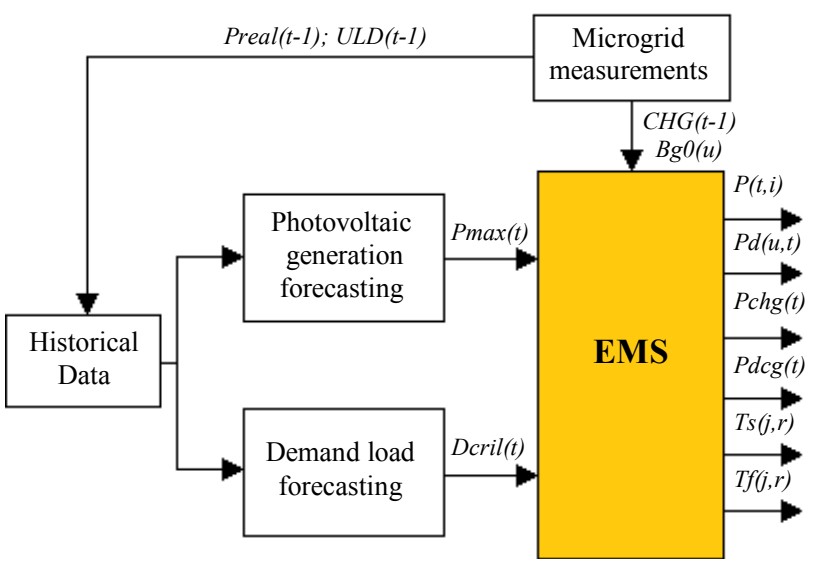

Fig. 1. EMS block chart.
- a discretized time horizon, and accordingly,

- the generation capacity for each non-renewable source,

- the generation prevision for each renewable source,

- the demand levels of loads over time,

- the energy storage limits and its initial level,

- the energy demand (modelled as next described), and

- penalty costs for not timely meeting demand, determine:

- the production level for each resource in each time interval and the timing of loads so that cost is minimized (including both, operational costs and penalty costs).

\section{Loads Characterization}

Energy loads are characterized according to basic models, leaving an expert modeller to decide the best option:

1) Uncontrollable loads: the aggregation of multiple loads that have little interest from the point of view of management. Aggregate levels are averaged for each time interval according to demand forecasts. The existence of a measurement system is assumed allowing the recording, processing and preparation of statistical forecast demand for a prediction horizon. This group of loads constitutes a demand profile.

2) Controllable loads: individual loads with interest from the point of view of management. They are modelled as preemptive loads inside a time window whose start and end are set based on the user needs. The consumption is considered at nominal power from begin to end (power peaks are not modelled).

\section{E. Modelling Considerations and Assumptions}

- A constant mean power value is assumed at each time interval for both the generation of renewable energy and the energy demand. The model makes no verification on the instantaneous power consumption of loads. So, the operational level is assumed to provide a fast enough response to manage power peaks.

- ESS self-discharge is disregarded.

- In the hierarchy of controllers the operations of the microgrid are at tactical level so it is assumed that the power quality meets the standards of electricity supplied by public electricity networks.

\section{F. Mathematical Formulation}

The problem to be solved by the EMS is the Mixed Integer Linear Program (MILP) next presented:

Renewable Sources: The average power supplied by renewable sources in each time interval $t$ is:

$$
P(t, i) \leq P \max (t, i) \times E f f(i) \quad \forall t, i
$$

\section{Problem Statement}

The problem addressed is stated as follows. Given: 
TABLE I

PARAMETERS

\begin{tabular}{|c|c|}
\hline Parameter & Description \\
\hline 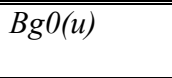 & $\begin{array}{l}\text { Non-renewable source u state at } \mathrm{t}=\mathrm{t} 0 \\
\text { ("0"=Turned off, " } 1 "=\text { Turned on) }\end{array}$ \\
\hline Bth & Absolute time start of the prediction horizon [s] \\
\hline$C d(u)$ & Start-up fixed cost of non-renewable source u [€] \\
\hline CHGmax & Maximum ESS energy level [kWh] \\
\hline CHGmin & Minimum ESS energy level [kWh] \\
\hline cpen1 & $\begin{array}{l}\text { Penalty cost for electricity not supplied to loads } \\
\text { (controllable and not) }[€ / \mathrm{kWh}]\end{array}$ \\
\hline cpen $2(j, r)$ & Earliness penalty cost of repetition $\mathrm{r}[€ / \mathrm{s}]$ \\
\hline $\operatorname{cpen} 3(j, r)$ & Tardiness penalty cost of repetition $\mathrm{r}[€ / \mathrm{s}]$ \\
\hline Csie; Dsie & Charge/Discharge efficiency of ESS inverter \\
\hline $\operatorname{Dcril}(t)$ & Uncontrollable loads consumption at $\mathrm{t}[\mathrm{kWh}]$ \\
\hline$D T$ & Span of the forecast interval [s] \\
\hline $\operatorname{Dur}(j, r)$ & Consumption duration of repetition $\mathrm{r}[\mathrm{s}]$ \\
\hline Eff(i) & Inverter efficiency of renewable power supply $i$ \\
\hline$E f f c ; E f f d$ & Charge/Discharge efficiency of ESS \\
\hline EngRef & Energy reference price of ESS [€/kWh] \\
\hline$N(u, v)$ & $\begin{array}{l}\text { Y-interception corresponding to the operating } \\
\text { cost curve linear segment } v\end{array}$ \\
\hline Pchgmax & Maximum charge nominal power of ESS [kW] \\
\hline Pchmin & Minimum charge nominal power of ESS [kW] \\
\hline Pdcgmax & Maximum discharge nominal power of ESS [kW] \\
\hline Pdcgmin & Minimum discharge nominal power of ESS [kW] \\
\hline $\operatorname{Pload}(j, r)$ & Power demand of repetition $\mathrm{r}[\mathrm{kW}]$ \\
\hline $\operatorname{Pmax}(t, i)$ & $\begin{array}{l}\text { Forecast maximum power supply of renewable } \\
\text { energy from source } i \text { at interval } t[\mathrm{~kW}]\end{array}$ \\
\hline $\operatorname{Pmn}(u, v)$ & $\begin{array}{l}\text { Minimum power supply corresponding to the } \\
\text { operating cost curve linear segment } \mathrm{v}[\mathrm{kW}]\end{array}$ \\
\hline $\operatorname{Pmx}(u, v)$ & $\begin{array}{l}\text { Maximum power supply corresponding to the } \\
\text { operating cost curve linear segment } \mathrm{v}[\mathrm{kW}]\end{array}$ \\
\hline$P \sin$ & Internal consumption of ESS inverter [kW] \\
\hline$S(u, v)$ & $\begin{array}{l}\text { Slope corresponding to operating cost curve } \\
\text { linear segment } \mathrm{v}\end{array}$ \\
\hline$T_{2}(j, r)$ & Earliness time of repetition $\mathrm{r}[\mathrm{s}]$ \\
\hline$T_{3}(j, r)$ & Tardiness time of repetition $\mathrm{r}[\mathrm{s}]$ \\
\hline$T f(j, r)$ & Consumption final time of repetition $\mathrm{r}[\mathrm{s}]$ \\
\hline$T s(j, r)$ & Consumption initial time of repetition $\mathrm{r}[\mathrm{s}]$ \\
\hline
\end{tabular}

TABLE II

DECISION VARIABLES

\begin{tabular}{l|l}
\hline \hline \multicolumn{1}{c|}{ Variable } & \multicolumn{1}{c}{ Description } \\
\hline \hline$P(t, i)$ & $\begin{array}{l}\text { Average power provision of renewable source } \mathrm{i} \text { at } \\
\text { interval } \mathrm{t} \text { (affected by the inverter efficiency) }[\mathrm{kW}]\end{array}$ \\
\hline$P c h g(t)$ & Charging power of ESS at $\mathrm{t}[\mathrm{kW}]$ \\
\hline$P d(u, t)$ & $\begin{array}{l}\text { Average power supply of the non-renewable source } \\
\mathrm{u} \text { at } \mathrm{t}[\mathrm{kW}]\end{array}$ \\
\hline$P d c g(t)$ & Discharging power of ESS at $\mathrm{t}[\mathrm{kW}]$ \\
\hline$T f(j, r)$ & Consumption final time of repetition $\mathrm{r}[\mathrm{s}]$ \\
\hline$T s(j, r)$ & Consumption initial time of repetition $\mathrm{r}[\mathrm{s}]$ \\
\hline \hline
\end{tabular}

TABLE III

BINARY VARIABLES

\begin{tabular}{l|l}
\hline \hline \multicolumn{1}{c|}{ Variable } & \multicolumn{1}{c}{ Description } \\
\hline \hline$B(u, v, t)$ & Selection of linear segment $\mathrm{v}$ at $\mathrm{t}$ \\
\hline$X b a t(t)$ & ESS state at $\mathrm{t}:$ " 1 "=Charging, "0"=Discharging \\
\hline$Y(t, j, r)$ & Repetition $\mathrm{r}$ start of consumption indicator at $\mathrm{t}$ \\
\hline$Z(t, j, r)$ & Repetition $\mathrm{r}$ end of consumption indicator at $\mathrm{t}$ \\
\hline \hline
\end{tabular}

TABLE IV

AUXILIARY VARIABLES

\begin{tabular}{|c|c|}
\hline Variable & "Description \\
\hline Cearli(j,r) & $\begin{array}{l}\text { Cost for begin before the earliness time of } \\
\text { repetition } \mathrm{r}[€]\end{array}$ \\
\hline $\operatorname{Cgen}(u, t)$ & Non-renewable fuel consumption cost at $\mathrm{t}[€ / \mathrm{kWh}]$ \\
\hline$C H G(t)$ & ESS energy level at $\mathrm{t}[\mathrm{kWh}]$ \\
\hline Cpen1t(t) & Penalty cost for energy not supplied to loads at $\mathrm{t}[€]$ \\
\hline Cpen $2 j(j)$ & $\begin{array}{l}\text { Penalty cost of controllable load } \mathrm{j} \text { for not meeting } \\
\text { timing constraints }[€]\end{array}$ \\
\hline Cpen $2 j(j, r)$ & $\begin{array}{l}\text { Penalty cost of repetition } r \text { for not meeting timing } \\
\text { constraints }[€]\end{array}$ \\
\hline$C s(u, t)$ & Start-up cost of the non-renewable source $u[€]$ \\
\hline Ctardi $(j, r)$ & $\begin{array}{l}\text { Cost for finish after the tardiness time of repetition } \\
\mathrm{r}[€]\end{array}$ \\
\hline $\operatorname{Dctrl}(t, j)$ & Energy demand of controllable load $\mathrm{j}$ at $\mathrm{t}[\mathrm{kWh}]$ \\
\hline $\operatorname{Dctrlr}(t, j, r)$ & Energy demand of repetition $\mathrm{r}$ at $\mathrm{t}[\mathrm{kWh}]$ \\
\hline EngPro(t) & Energy supplied to loads at $\mathrm{t}[\mathrm{kWh}]$ \\
\hline $\operatorname{EngVal}(t)$ & $\begin{array}{l}\text { Economic valuation of the energy transition from } \\
t-1 \text { to } t[€]\end{array}$ \\
\hline $\operatorname{Load}(t)$ & Charging energy of ESS at $\mathrm{t}[\mathrm{kWh}]$ \\
\hline$O(t, j, r)$ & Consumption period of repetition $\mathrm{r}$ at $\mathrm{t}[\mathrm{s}]$ \\
\hline$S P(t)$ & Discharging energy of ESS at $\mathrm{t}[\mathrm{kWh}]$ \\
\hline $\operatorname{TotalB}(t)$ & Economic evaluation at $\mathrm{t}[€]$ \\
\hline
\end{tabular}

Energy Storage System (ESS): The ESS charge and discharge power must be between a maximum and a minimum set by a binary variable Xbat that indicates if the ESS is charging or discharging in a time interval. So $\forall t$ :

Pchgmin $\times$ Xbat $\leq P \operatorname{chg}(t) \leq P$ chgmax $\times$ Xbat

$P d c g$ min $\times(1-X b a t) \leq P d c g(t)$

$$
\begin{gathered}
\leq P d \operatorname{Pdgmax} \times(1-X b a t) \\
\operatorname{Load}(t)=\operatorname{Pchg}(t) \times \frac{D T}{3600} \\
S P(t)=\operatorname{Pdcg}(t) \times \frac{D T}{3600}
\end{gathered}
$$

Another EMS function is to allow the ESS to work between the discharge limits, so the following restrictions should be considered:

$$
\begin{array}{rlrl}
C H G(t) & \leq C H G \max & & \forall t \\
C H G(t) \geq C H G \min & & \forall t
\end{array}
$$

The energy balance in each time interval is:

$$
\frac{S P(t)}{E f f d}-\operatorname{Load}(t) \times E f f c=C H G(t-1)-C H G(t) \forall t
$$

Non-Renewable Sources: The model assumes the linearization of the demand curve based on the generated power and hence the costs function as in [6]. Thus, for each time interval (and power output) an associated cost is obtained. The average power supply of a non-renewable source in the interval $t$ is given by:

$$
P d(u, t)=\sum_{v=v 1}^{V} \operatorname{Pt}(u, v, t) \quad \forall u, t
$$


$\operatorname{Pmn}(u, v) \times B(u, v, t) \leq \operatorname{Pt}(u, v, t)$

$$
\leq \operatorname{Pmx}(u, v) \times B(u, v, t) \quad \forall u, v, t
$$

Where $B(u, v, t)$ is a binary variable, and $\operatorname{Pt}(u, v, t)$ is the average power given by the generator in each of the segments in which we divide the demand curve. Only one variable $B(u, v, t)$ takes the value 1 in any period:

$$
\sum_{v=v 1}^{V} B(u, v, t) \leq 1 \quad \forall u, t
$$

Controllable Loads: For each repetition $r$ of controllable load $\mathrm{j}(j, r)$ the consumption start time will be bounded by:

$$
\operatorname{Tin}(j, r) \leq T s(j, r) \leq T f \max (j, r)-\operatorname{Dur}(j, r) \quad \forall j, r
$$

The consumption final time is formulated as:

$$
\begin{gathered}
T f(j, r)=T s(j, r)+\operatorname{Dur}(j, r) \quad \forall j, r \\
T f(j, r) \leq T h+B t h \quad \forall j, r
\end{gathered}
$$

The model is based on two binary variables that represent the relative position of $(j, r)$ over any time interval as in [7]: the variable $Y(t, j, r)$ indicates the start of consumption $(j, r)$ and is equal to 1 if $(j, r)$ begins before or during the time interval, and takes the value 0 otherwise, the variable $Z(t, j, r)$ indicates the completion of consumption and is equal to 1 if $(j, r)$ ends before or during the interval $t$, and takes the value 0 otherwise as shown in Fig. 2:

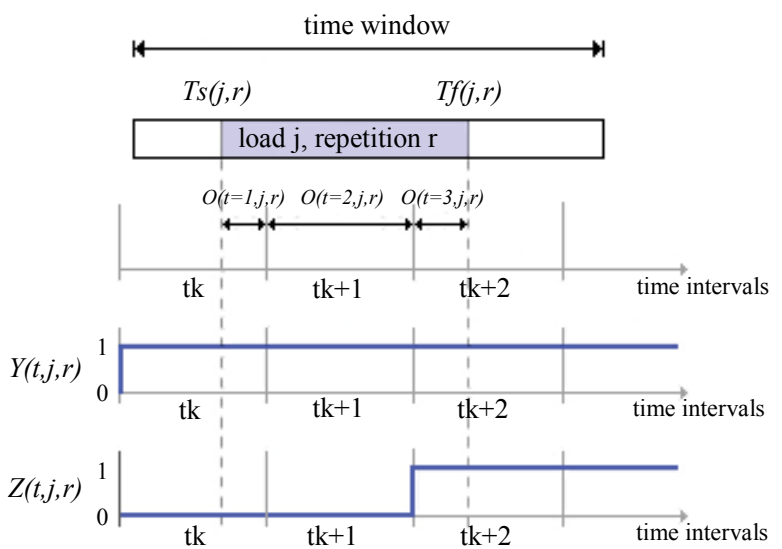

Fig. 2. Consumption intervals and binary variables of start and end.

The corresponding constraints $\forall t \neq T$ and $\forall j, r$ are:

$$
T s(j, r) \geq[(D T \times \zeta)+B t h] \times[1-Y(t, j, r)]
$$$$
T s(j, r) \leq[(D T \times \zeta)+B t h]
$$$$
+(T h+B t h) \times[1-Y(t, j, r)]
$$

If in a given period a variable $Y(t, j, r)=1$, from that moment until the end of the prevision horizon that variable will have the value 1 :

$$
Y(t+1, j, r) \geq Y(t, j, r) \quad \forall t \neq T
$$

The value of $Y(t, j, r)$ at the end of the prevision horizon must be 1:

$$
Y(t, j, r)=1 \quad \forall t=T
$$

The end time $T f(j, r)$ is restricted similarly to $T s(j, r)$ and $Z(t, j, r)$ similarly to $Y(t, j, r)$ as it is expressed in (15), (16), (17) and (18).

For each $(j, r)$ scheduled between $T s(j, r)$ and $T f(j, r)$, the consumption period in interval t, $O(t, j, r)$, is positive and limited by the length of the time interval DT. Thus:

$$
\begin{aligned}
& O(t, j, r) \leq D T \times[Y(t, j, r)-Z(t-1, j, r)] \quad \forall t, j, r \\
& O(t, j, r) \geq D T \times[Y(t-1, j, r)-Z(t, j, r)] \quad \forall t, j, r
\end{aligned}
$$

And $\forall t \neq T ; \forall j, r$ :

$$
\begin{array}{r}
O(t, j, r) \geq T f(j, r)-[(D T \times \zeta)+B t h]+D T \\
\times Y(t-1, j, r)-(T h+B t h) \times[1-Z(t, j, r)] \\
O(t, j, r) \geq[(D T \times \zeta)+B t h] \times[1-Y(t-1, j, r)] \\
-T s(j, r)-D T \times Z(t, j, r)
\end{array}
$$

Finally, the total consumption time in each time interval inside the prediction horizon is equal to its length:

$$
\sum_{t=t 1}^{T} O(t, j, r)=\operatorname{Dur}(j, r) \quad \forall j, r
$$

The total energy demand at each interval is:

$$
\operatorname{Dctrlr}(t, j, r)=\operatorname{Pload}(j, r) \times \frac{o(t, j, r)}{3600} \quad \forall t, j, r
$$

The power provided to the loads in each time interval must be less or equal than the total energy demand, then:

$$
\operatorname{EngPro}(t) \leq \operatorname{Dcril}(t)+\sum_{j=j 1}^{J} \operatorname{Dctrl}(t, j) \quad \forall t
$$

Where the total demand of controllable load $\mathrm{j}$ is the sum of all its repetitions in each time interval:

$$
\operatorname{Dctrl}(t, j)=\sum_{r=r 1}^{R} \operatorname{Dctrl}(t, j, r) \quad \forall t, j
$$

The energy balance in each time interval is:

$$
\begin{array}{r}
\sum_{i=i 1}^{I}\left[P(t, i) \times \frac{D T}{3600}\right]+\left\{S P(t) \times D \text { sie }-\frac{\operatorname{Load}(t)}{C \operatorname{sie}}-P \sin \times\right. \\
\left.\frac{D T}{3600}\right\}+\sum_{u=u 1}^{U}\left[P d(u, t) \times \frac{D T}{3600}\right]-\operatorname{EngPro}(t)=0 \quad \forall t(27)
\end{array}
$$

Costs: A penalty cost is considered for any $(j, r)$ failing to meet energy requirements:

$$
\begin{array}{r}
\operatorname{Cpen} 1 t(t)=\operatorname{cpen} 1 \times\left[\left(\operatorname{Dcril}(t)+\sum_{j=j 1}^{J} \operatorname{Dctrl}(t, j)\right.\right. \\
-\operatorname{EngPro}(t)] \quad \forall t
\end{array}
$$


In addition, an increasing penalty is applied if consumption starts before its earliest bound, $T_{2}(j, r)$, and/or ends later than its latest bound, $T_{3}(j, r)$ :

$\operatorname{Cearli}(j, r) \geq \operatorname{cpen} 2(j, r) \times\left(T_{2}(j, r)-T s(j, r)\right) \quad \forall j, r(29)$

Ctardi $(j, r) \geq \operatorname{cpen} 3(j, r) \times\left(T f(j, r)-T_{3}(j, r)\right) \forall j, r(30)$

$\operatorname{Cpen} 2(j, r)=\operatorname{Cearli}(j, r)+\operatorname{Ctardi}(j, r) \forall j, r(31)$

The total penalty cost for each controllable load $(j)$ is the sum of those expressed in (31):

$$
\operatorname{Cpen} 2 j(j)=\sum_{r=r 1}^{R} \operatorname{Cpen} 2(j, r) \quad \forall j
$$

The fuel consumption curve of a non-renewable source is modelled by dividing the domain in $\mathrm{V}_{\mathrm{u}}$ line segments, so fuel costs can be expressed as:

$$
\begin{array}{r}
\operatorname{Cgen}(t)=\sum_{u=u 1}^{U}\left\{\sum_{v=v 1}^{V}[S(u, v) \times P(u, v, t)+N(u, v)\right. \\
\times B(u, v, t)]\} \times \frac{D T}{3600} \forall t
\end{array}
$$

The positive variable $C s(u, t)$ is the start-up cost of the nonrenewable source; it will take a positive value only when $B(u, v, t)$ changes its value from 0 (off) to 1 (on) in two successive iterations:

$$
\begin{aligned}
C s(u, t) & \geq C d(u) \\
& \times\left[\sum_{v=v 1}^{V} B(u, v, t)-\sum_{v=v 1}^{V} B(u, v, t-1)\right]
\end{aligned}
$$

The parameter EngRef valorises the energy exchange of the ESS by inserting a benefit or cost with low significance (the objective function decreases when charging and increases when discharging). The parameter value should be small enough not to significantly affect the value of the objective function. Thus:

$$
\operatorname{EngVal}(t)=\operatorname{EngRef} \times[C H G(t)-C H G(t-1)] \forall t
$$

The economic balance in each time interval $t$ is:

$$
\begin{aligned}
& \operatorname{TotalB}(t)=\operatorname{Cpen} 1 t(t)+\sum_{u=u 1}^{U} \operatorname{Cgen}(u, t) \\
& +\sum_{u=u 1}^{U} \operatorname{Cs}(u, t)-\operatorname{EngVal}(t) \forall t
\end{aligned}
$$

The value of the objective function (total economic balance) is calculated as:

$$
\begin{aligned}
& \text { Minimize TotalBal }= \\
& \qquad \sum_{t=t 1}^{T}[\operatorname{TotalB}(t)]+\sum_{j=j 1}^{J} \sum_{r=r 1}^{R}[\operatorname{Cpen} 2(j, r)]
\end{aligned}
$$

\section{ROLLING HORIZON CONTROL STRATEGY}

The rolling horizon technique consists on applying the control actions during a period of time, after which the system state is updated and a new optimization problem is solved. The microgrid behaviour is subsequently estimated and new control actions are determined and applied.
The rolling horizon strategy confers an iterative nature to the problem: given initial conditions, a deterministic model is solved and a plan is drawn. Only the information of the first period of this plan is applied for controlling devices. After a time period the initial conditions for the next optimization run are updated with the forecast information and measurements of the devices (i.e. in each iteration as the horizon slides and the initial conditions are reformulated for the next iteration).

To address the problem, an interface was developed that together with the optimization program performed the following sequence of steps:

1. Initialize the problem.

2. Activate the optimization program and run the solver.

3. Store the optimization results for the entire prevision horizon.

4. Advance the prevision horizon and prepare initial conditions for the next iteration.

5. Wait for the completion of the current interval.

6. Read the state of the microgrid devices, update the initial conditions and return to Step 2.

Figure 3 shows how the rolling horizon control strategy works: in the upper graph, given a forecast of renewable power generation, the model provides the schedule of controllable loads. In the next iteration (lower graph) the forecasts are updated and after a new optimization a new schedule is obtained. At the level of distributed generators and EMS planning, all the information in the first time slot of this plan is used (set-points) and at the demand level, all the loads planned to start in this first interval will be executed in the next iteration.

To solve successive MILP problems, the prototype uses the CPLEX solver (version 12.3.0.0 [8]) included in the GAMS commercial software [9]. The interface was developed in MSExcel spreadsheets programmed with VBA macros [10]. The GAMS Data Exchange utility GDXXRW was used for creating the exchange files (.GDX files) between GAMS and the MS-Excel interface [11].

\section{CASE STUDY}

The proposed control strategy is tested in a microgrid composed of a photovoltaic generation system, a diesel generator, a SAEE and a set of loads. Table V shows the microgrid devices technical information.

\section{A. Problem formulation:}

Given the parameterization for 5 controllable loads, the objective is to compare the microgrid behaviour in two cases: with and without demand management (WDM and WODM). In the latter case, consumption times are fixed; hence the operation of the microgrid only requires the management of energy generation. 

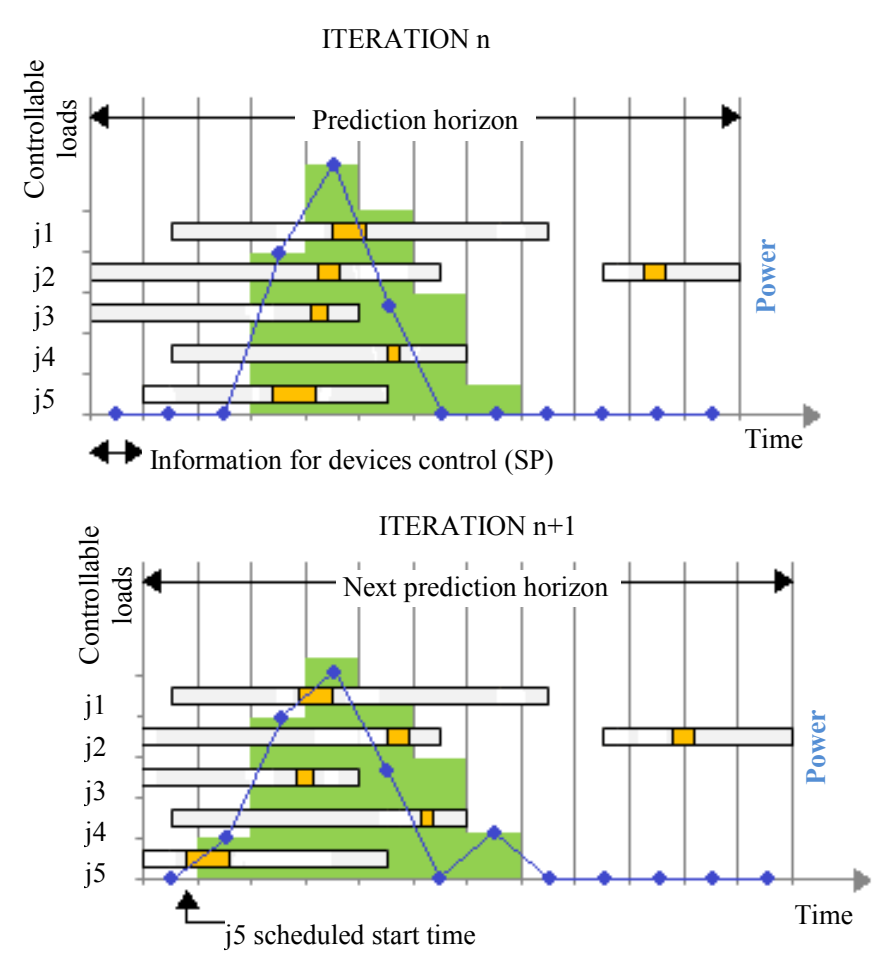

$\square \begin{aligned} & \text { Renewable generation power forecast } \\ & \square \text { Generation power optimal scheduling } \\ & \text { C Controllable demand optimal scheduling }\end{aligned}$

Fig. 3. Rolling horizon control strategy operation

TABLE V

MG DEVICES TECHNICAL INFORMATION

\begin{tabular}{|c|c|c|c|c|c|}
\hline \multicolumn{6}{|c|}{ Photovoltaic generator } \\
\hline Nominal Power $[\mathrm{kW}$ & & & & & $\overline{14,4}$ \\
\hline \multicolumn{6}{|c|}{ Diesel generator } \\
\hline \multicolumn{4}{|c|}{ Maximum Power [kW]: } & & 6,6 \\
\hline \multicolumn{4}{|c|}{ Start up fixed cost $[€]$ : } & & 5 \\
\hline \multicolumn{4}{|l|}{ Initial condition: } & & Off \\
\hline \multicolumn{4}{|c|}{ Diesel fuel price [€/liter] [12]: } & & 1,4 \\
\hline \multicolumn{6}{|l|}{ Demand curve [13]: } \\
\hline Load & $1 / 4$ & $1 / 2$ & $3 / 4$ & Full & \\
\hline Liter/hour & 1,54 & 1,87 & 2,31 & 2,86 & \\
\hline \multicolumn{6}{|c|}{ EMS } \\
\hline \multicolumn{4}{|c|}{ Maximum operating power level [kWh]: } & & 28,8 \\
\hline \multicolumn{4}{|c|}{ Maximum deep of discharge [\%]: } & & 80 \\
\hline \multicolumn{4}{|c|}{ Initial energy level[kWh] : } & & 17,28 \\
\hline \multicolumn{4}{|c|}{ Maximum charge power $[\mathrm{kW}]$ : } & & 5 \\
\hline \multicolumn{4}{|c|}{ Minimum charge power $[\mathrm{kW}]$ : } & & 0 \\
\hline \multicolumn{4}{|c|}{ Maximum discharge power $[\mathrm{kW}]$ : } & & 5 \\
\hline \multicolumn{4}{|c|}{ Minimum discharge power [kW]: } & & 0 \\
\hline \multicolumn{4}{|l|}{ Charge efficiency: } & & 0,6 \\
\hline \multicolumn{4}{|l|}{ Discharge efficiency: } & & 0,6 \\
\hline \multicolumn{4}{|c|}{ Inverter charge efficiency: } & & 0,94 \\
\hline \multicolumn{4}{|c|}{ Inverter discharge efficiency: } & & 0,94 \\
\hline \multicolumn{4}{|c|}{ Inverter internal consumption $[\mathrm{kW}]$ : } & & 0,02 \\
\hline \multicolumn{4}{|c|}{$\begin{array}{l}\text { Inverter internal consumption }[\mathrm{KW}] \text { : } \\
\text { Energy reference price }[€ / \mathrm{kWh}]:\end{array}$} & & 0001 \\
\hline
\end{tabular}

\section{RESULTS}

The results were obtained considering a prediction horizon of 24 hours with time intervals of 1 hour, for 30 days. To make the results comparable, historical values of renewable generation and uncontrollable demand obtained from a real microgrid operation were used. Table VI summarizes the simulation results:

TABLE VI

SIMULATION RESULTS

\begin{tabular}{l|c|c|c}
\hline \hline \multicolumn{1}{c|}{ MG Operation indicator } & WODM & WDM & Variation \\
\hline \hline Diesel generator cost operation [€]: & 559 & 496 & $\mathbf{- 1 1 , 3 \%}$ \\
\hline Diesel generator star-ups: & 33 & 34 & $+3 \%$ \\
\hline $\begin{array}{l}\text { Energy produced by de Diesel } \\
\text { generator [kWh]: }\end{array}$ & 587 & 430 & $\mathbf{- 2 6 , 7 \%}$ \\
\hline $\begin{array}{l}\text { EMS number of charge/ discharge } \\
\text { cycles: }\end{array}$ & 30 & 27 & $\mathbf{- 1 0 \%}$ \\
\hline $\begin{array}{l}\text { Average deep of discharge per cycle } \\
\text { [\%]: }\end{array}$ & 45 & 39 & $\mathbf{- 1 3 , 8 \%}$ \\
\hline Renewable resource utilization [\%]: & 33 & 69,4 & - \\
\hline CO2 emissions [kgCO2/month] & 768 & 633 & $\mathbf{- 1 7 , 6 \%}$ \\
\hline \hline
\end{tabular}

For the case WDM the operating cost of the diesel generator is reduced by $11.3 \%$, which is mainly due to a better exploitation of the renewable resource (WDM mode uses almost $27 \%$ less energy from non-renewable source).

Furthermore, reducing both EMS charge/discharge cycles and the average discharge depth are additional benefits (the EMS life-cycle is extended). This behaviour is due to the fact that controllable loads tend to be allocated within significant renewable energy generation periods, which produces discharges shallower than those obtained for the WODM case.

Finally, demand management also reduces the environmental impact. In this specific case, it prevents the emission of 1.62 tonnes of $\mathrm{CO}_{2}$ per year approx., caused by the combustion of the corresponding diesel fuel.

\section{CONCLUSIONS}

This work presents an EMS prototype for isolated microgrid management based on a rolling horizon control strategy. The EMS provides set points for the generating units and the novelty introduced is the possibility of dynamically managing the timing of a set of controllable loads to minimize the microgrid operational cost. The rolling horizon control strategy allows working with forecasts and updated data, thus reactively reducing the effects of the uncertainty on both the generation capacity and the demand.

The results obtained with the prototype developed show the importance of demand management. Significant economic benefits are obtained compared to the fixed demand program, mainly due to the better use of the renewable resource. Last but not least, demand management produces environmental benefits associated with the emission of $\mathrm{CO}_{2}$.

Future work could address the extension of the model to consider different types of energy sources and types (e.g. thermal and electrical), the connection to the utility grid (purchase and sale of electrical energy) and the typification of 
other controllable loads (e,g. non-preemptive loads). In addition to that, modelling uncertainty with the incorporation of weather or demand uncertainty are interesting research aspects for future developments.

\section{REFERENCES}

[1] D. E. Olivares, C. A. Cañizares and M. Kazerani, "A centralized optimal energy management system for microgrids", in 2011 IEEE Power and Energy Society General Meeting, 2011, ISSN 1944-9925, p. 1.

[2] D. Limón Marruedo, "Constrained non-linear systems predictive control: stability and robustness". Ph.D. Eng. thesis, Superior Engineering School of the University of Sevilla, Sevilla, Spain, Sep. 2002.

[3] H. Dagdougui, R.Minciardi, A. Ouammi, M. Robba and R. Sacile, "A dynamic decision model for the real-time control of hybrid renewable energy production systems", IEEE Syst. J., vol. 4, no. 3, pp. 323-333,

Sep. 2010

[4] E. R. Sanseverino, M. L. Di Silvestre, M. G. Ippolito, A. De Paola, G. Lo $\mathrm{Re}$, "An execution, monitoring and replanning approach for optimal energy management in microgrids", Energy, vol. 36, pp. 3429-3436, Apr. 2011.

[5] A. Parisio and L. Glielmo, "Energy efficient microgrid using model predictive control", in 2011 50th IEEE Conference on Decision and Control and European Control Conference (CDC-ECC), 2011, ISSN 0743-1546, p. 5449-5454.

[6] R. Palma-Behnke, C. Benavidez, F. Lamas, B. Severino, L. Reyes, J. Llanos and D. Saez, "A microgrid energy mangement system based on the rolling horizon strategy”, IEEE Transactions on Smart Grid, vol. 4, issue 2, pp. 996-1006, Jun. 2013.

[7] A. Hait and C. Artigues, "On electrical load tracking scheduling for a steel plant”, Computers and Chemical Engineering, vol. 35, issue 12, pp. 30443047, Mar. 2011.

[8] (2013) The IBM website on CPLEX. [Online]. Available: http://www01.ibm.com/software/commerce/optimization/cplex-optimizer/

[9] (2013) The GAMS website. [Online]. Available: http://www.gams.com [10] (2013) The Microsoft Office websisite on VBA macros. [Online].

Available: http://msdn.microsoft.com/es-es/office/ff688774.aspx

[11] (2013) The McCarl GAMS User Guide Version 24.0 on GAMS website. [Online]. Available:

http://www.gams.com/dd/docs/bigdocs/gams2002/mccarlgamsuserguide.pdf, pp. 612-634

[12] (2013) The Catalunya government website on energy prices. [Online].

Available: www.gencat.cat/icaen/preus

[13] X-Series 6,6kW Diesel Generator (C8D5), Cummings, 2013 